\title{
Desenvolvimento de questionário dirigido às condições de moradia de usuários de CAPS
}

Development of questionnaire to the dwelling conditions of CAPS users

Juarez Pereira Furtado', Maria Inês Badaró Moreira², Sônia Nozabielle³, Terezinha de Fátima

Rodrigues ${ }^{4}$, Fábio Montesano 5

' Doutorado em Ciências Médicas pela Universidade Estadual de Campinas (UNICAMP) - Campinas (SP), Brasil. Professor Adjunto III do Departamento Saúde, Educaçăo e Sociedade da Universidade Federal de São Paulo (USP), São Paulo (SP), Feder

juarezpfurtado@hotmail.com

${ }^{2}$ Doutorado em Psicologia pela Universidade Federal do Espírito Santo (UFES) - Vitória (ES), Brasil. Professora Adjunta II do Departamento Saúde, Educação e Sociedade da

Universidade Federal de São Paulo (UNIFESP) - São Paulo (SP), Brasil.

mibadaro@gmail.com

${ }^{3}$ Doutorado em Serviço Social pela Pontifícia Universidade Católica de São Paulo (PUC São Paulo) - São Paulo (SP), Brasil. Professor Adjuntol do Departamento Saúde, Educação e Sociedade da Universidade Federal de São Paulo (UNIFESP) - São Paulo (SP), Brasil. soniamark@ig.com.br

${ }^{4}$ Doutorado em Serviço Social pela Pontifícia Universidade Católica de São Paulo (PUC São Paulo) - São Paulo (SP), Brasil. Professor Adjunto I do Departamento Saúde, Educação e Sociedade da Universidade Federal de São Paulo (UNIFESP) - São Paulo (SP), Brasil.

terodrigues@ig.com.br

${ }^{5}$ Graduação em Estatística pela Universidade de São Paulo (USP) - São Paulo (SP), Brasil. Técnico do Programa de Pós-graduação da Universidade Federal de São Paulo, Campus Baixada Santista (UNIFESP) - Santos (SP),

Brasil.

fmontesano@unifesp.br
RESUMO Apresentamos instrumento voltado às condições de moradia dos portadores de sofrimento mental grave, atendidos pelos Centros de Atendimento Psicossocial (CAPS). Por meio da técnica de Delphi e da participação de trabalhadores de CAPS, definimos uma versão preliminar do questionário que foi finalizada após pré-teste em três diferentes municípios paulistas. O questionário final resultou em 71 itens e 5 blocos referentes aos aspectos clínicos, socioeconômicos, característica do imóvel, inserção social, autonomia e satisfação com a habitação. O questionário sobre moradia e habitação de portadores de sofrimento psíquico grave encontra-se pronto para aplicação em escala ampliada..

PALAVRAS CHAVE: Questionário; habitação; saúde mental; reforma psiquiátrica.

\begin{abstract}
We expose questionnaire on dwelling conditions of people with severe mental suffering, assisted by the Centers for Psychosocial Care (CAPS). Through the Delphi technique and participation of workers CAPS define a preliminary version of the questionnaire was finalized after pre-testing in three different counties. The final questionnaire resulted in 71 items and 5 blocks relating to clinical aspects, socio-economic characteristics of the property, social integration, autonomy and satisfaction with housing. The questionnaire on housing and housing for people with severe psychological distress is ready for implementation on a larger scale.
\end{abstract}

KEYWORDS: Questionnaire; housing; mental health; psychiatric reform. 


\section{Moradia: de necessidade subjetiva a direi- to social}

Para Rybczynski (1996), a ideia de casa, tal como a compreendemos hoje, é relativamente recente em nossa sociedade. Até o século XVI, o espaço para morar não era subdividido, os cômodos das residências tinham múltiplas funçôes de acordo com o horário do dia e a atividade de seus moradores. Era uma casa grande, povoada, um lugar no qual o público e o privado não eram distintos (ARIÈS, 1986). As noções de 'doméstico' e 'privado' originam-se com a era burguesa, definindo o lar como espaço da família e da intimidade (RYBCZYNSKI, 1996; SENNET, 1988; ARIÈS, 1986).

Em uma perspectiva voltada ao desenvolvimento e constituição do sujeito, a importância do lar é decisiva na formação de nossa subjetividade, sendo a casa um polo integrador de vivências, pensamentos, lembranças e sonhos, sem a qual seríamos seres dispersos (BRANDÁO, 2002). Assim, se existe uma casa como um lugar objetivo, há também uma casa subjetiva, revelada pela experimentação de quem a habita. Bachelard (1988) destaca as possibilidades originadas no lar para o sonho e o devaneio e suas características de proteção e abrigo, permitindo habitar o mundo apesar do mundo.

Uma casa pode constituir espaço de exercício afirmativo que assevera a singularidade de seu morador. Por mais simples que seja, a morada representa proteção do mundo externo, muitas vezes vivido como especialmente ameaçador pelo portador de sofrimento psíquico grave (MOREIRA, 2007). O local de moradia ocupa centralidade no processo de constituição e desenvolvimento do indivíduo, convergindo para um mesmo espaço a possibilidade de escape ao olhar público em direção à intimidade e, ao mesmo tempo, sendo ponto privilegiado ao estabelecimento de relaçóes e manutenção de afetos de diversas ordens (MORIN et al., 2001). A moradia representa importante papel para a qualidade de vida, configurando-se determinante social da saúde em geral (THOMSON et al., 2009) e para a saúde mental, como também para a reinserção de pessoas que vivem sofrimento psíquico grave em particular (BEAULIEU et al., 2004).

Reconhecida como direito universal do homem pela ONU, em 1948, a moradia foi incluída tardiamente na Constituição Federal de 1988 como direito social, por meio da Emenda Constitucional 26/2000. A partir de Sposati (2007), é possível compreender que o âmbito de uma política social resulta de um conjunto articulado de processos sociais, econômicos, históricos e políticos e daquelas orientaçóes estabelecidas pela sociedade quanto às responsabilidades, sejam públicas ou privadas, para prover as necessidades de reprodução social, ou seja, "aquelas que transitam da responsabilidade individual e privada para a responsabilidade social e pública" (SPOSATI, 2007, p. 3).

\section{O problema: moradia na era pós-asilar}

Se os portadores de sofrimento psíquico grave já viveram livres em épocas remotas, sabemos, por outro lado, que por duzentos anos o hospital psiquiátrico tornouse local privilegiado para sua inserção, a partir do início do século XIX, na Europa (FOUCAULT, 1991) e início do século XX, no Brasil (AMARANTE, 1994). Para Saraceno (1999), a questão da psiquiatria foi, em grande parte, a busca de uma residência para o louco, constituindo "o manicômio como residência coagida, controlada, expropriada, mas residência” (p. 114). A relação social estabelecida com o chamado louco, caracterizada pela segregação e isolamento, acabou por expandir a função social dos hospitais psiquiátricos: uma vez inseridos nessas instituiçôes, boa parte permanecia indefinidamente na condição de internos, formando uma legião de pacientes quase sem vínculos com seu meio sociofamiliar de origem, passando a constituir o que é corriqueiramente chamado de 'moradores'. Esta condição ainda é comum a milhares de internos nessas instituiçóes, como se pode depreender a partir do censo realizado, no estado de Sáo Paulo, por Barros e Bichaff (2008).

O progressivo fechamento de leitos hospitalares psiquiátricos, no contexto da reforma psiquiátrica brasileira, estimulou o surgimento de iniciativas voltadas 
a receber esses 'moradores' - egressos de longas internações psiquiátricas - a partir da constituição de casas inseridas em espaços urbanos chamadas, em algumas experiências pioneiras de início dos anos 1990, de "moradias extra-hospitalares" (FURTADO et al., 1998). Somente a partir do início do século atual, em 2001, por meio de portaria do Ministério da Saúde, que tais iniciativas passam a ser normatizadas e financiadas pelo SUS, nomeadas como Serviços Residenciais Terapêuticos (SRT) (BRASIL, 2004).

Atualmente, o Brasil possui 32 mil leitos psiquiátricos, resultado da redução de aproximadamente 84 mil leitos nos últimos 11 anos. Existem 779 SRTs em funcionamento, nos quais moram 3.091 pessoas de ambos os sexos (BRASIL, 2012). Porém, em que pese o contínuo declínio dos leitos psiquiátricos, o relativo sucesso dos SRTs em inserir seus moradores no espaço urbano e a vontade política para sua expansão, o número existente esteve sempre muito aquém do necessário, respondendo por uma pequena fração das reais necessidades da clientela de longa internação (FURTADO, 2006).

Somente no estado de São Paulo, foram identificados 6.349 'moradores' em hospitais no censo citado (BARROS, BICHAFF, 2008), o que requereria triplicar o número de SRTs existentes no Brasil para atender a potencial clientela desse estado brasileiro. Por outro lado, excluindo-se aqueles destinados a dependentes químicos e à infância, temos 1.470 CAPS voltados aos portadores de sofrimento psíquico grave no Brasil, sendo 215 no estado de São Paulo (BRASIL, 2012). Levando-se em conta estudos feitos por Kantorski et al. (2010), podemos considerar em mais de 21 mil o número de portadores de sofrimento psíquico grave acompanhados por esses serviços em todo o país, estimando que cada um deles se ocupe de, ao menos, cem pacientes graves.

Nesse contexto de superação da centralidade do hospital psiquiátrico, oferta de alternativas de moradia restrita aos SRTs e estímulo ao tratamento na comunidade, cabe indagar sobre como os milhares de portadores de sofrimento psíquico grave no estado de São Paulo constituem e efetivamente sustentam suas moradias. As moradias do cidadão portador de sofrimento psíquico grave, para além daqueles inseridos nos Serviços Residenciais Terapêuticos (SRT) do Sistema Único de Saúde (SUS), no contexto da reforma da assistência em saúde mental no Brasil, é uma questão ainda não suficientemente debatida e abordada (FURTADO et al., 2010) de forma pública. 'Público' aqui entendido como o

espaço essencialmente politico de aparecimento e visibilidade, onde [...] os sujeitos sociais estabelecem uma interlocução pública, que não é apenas discursiva, mas implica a ação e a deliberação sobre questóes que dizem respeito a um destino comum/coletivo. (RAICHELIS, 2000, p. 8).

Em pesquisa recentemente concluída (FURTADO et al., 2010), por meio do acompanhamento em profundidade de alguns casos em diferentes estados do Brasil, verificou-se que os usuários de serviços de saúde mental moram de muitas e diversas maneiras e que seus modos de morar são fatores importantes na evolução de seu quadro e sua maior ou menor inserção na sociedade em geral e na rede de cuidados em particular. Porém, tal diversidade de morar precisa ser mais bem compreendida em escalas ampliadas, junto ao universo de portadores de TMG.

A partir das questóes identificadas nos resultados preliminares de estudo qualitativo (FURTADO et al., 2010), percebe-se a necessidade de conhecer novos e mais aspectos ligados às relaçôes entre moradia e inserção social, ampliando sua abrangência. Para isso, nos lançamos ao trabalho de elaboração de um instrumento, na forma de questionário, contendo perguntas dirigidas aos aspectos subjetivos, sociais, assistenciais e físicos envolvidos com a moradia e o morar de usuários das redes de CAPS do estado de São Paulo ${ }^{1}$.

A pesquisa foi aprovada pelo Comitê de Ética (NBBS 055/11) e contou com financiamento do CNPq (edital 014/2010). 


\section{Desenvolvimento, qualificação e teste do instrumento}

\section{Ponto de partida}

O primeiro conjunto de questóes para a elaboração do questionário teve como ponto de partida vivências e reflexôes oriundas de nossa pesquisa qualitativa e interdisciplinar sobre habitação e inserção social (FURTADO et al., 2010). Os participantes da pesquisa eram moradores de SRT e demais usuários de CAPS que estabeleciam seus espaços de moradia de distintas maneiras em casas, apartamentos, pensóes, albergues ou em situação de rua, como sem-tetos.

Por meio dos estudos acima citados, compreendemos também a importância da consideração de aspectos físicos, relacionais e subjetivos intimamente relacionados na estruturação e manutenção dos espaços de moradia, o que exige a articulação de saberes intersetoriais e interdisciplinares. Por essa razão, a equipe de pesquisadores responsáveis pela elaboração desta pesquisa e, por conseguinte, do questionário, foi composta por profissionais oriundos do Serviço Social, Psicologia e Saúde Coletiva, além de um estatístico. Nesta equipe manteve-se o cuidado de que as diferenças pudessem estabelecer diálogos, complementaridades e que os eventuais tensionamentos culminassem em reelaboraçóes coletivas sem necessariamente chegar a unificaçóes, já que compreendemos a interdisciplinaridade como o convívio e articulação das diferenças e não como homogeneização de formas de pensar ou agir (FURTADO, 2007).

Além de pesquisas anteriores e das contribuições das áreas do conhecimento citadas, documentos e investigaçóes como a Pesquisa de Condições de Vida (SÃO PAULO, 2006), o questionário da Pesquisa Nacional por Amostra de Domicílios (PNAD) (INSTITUTO BRASILEIRO DE GEOGRAFIA E ESTATÍSTICA, 2009) e trabalhos acadêmicos como o estudo português sobre realojamento e satisfação residencial (ALMEIDA et al., 2002), a discussão sobre adequação residencial (VETTER, 1981) e a avaliação das condições de habitação e saneamento na perspectiva do trabalho domiciliar (AZEREDO et al., 2007) constituíram especial fonte de subsídios e pontos de partida à consolidação da versão preliminar do instrumento a ser analisada por meio da técnica de Delphi. Versão final e completa do questionário pode ser vista ao final do presente texto (Anexo I).

\section{Delphi modificada}

Com seu nome inspirado no Oráculo de Delfos, dedicado principalmente a Apolo, ao qual se dirigiam os antigos gregos para remeterem questóes aos deuses (JONES; HUNTER, 1995), a técnica de Delphi foi desenvolvida nos EUA, nos anos 1950, inicialmente como instrumento para previsóes sobre temas militares, passando depois a ser aplicada à prediçáo no campo empresarial, de tecnologias e na sociologia da saúde (PIOLA et al., 2002). Por meio de consulta a um grupo selecionado, segundo o acúmulo reconhecido no problema abordado, busca-se a obtenção de opiniôes coletivas e qualificadas sobre o tema predefinido (LANDETA, 1999).

Em nosso caso, foram convidados dez indivíduos considerados pela equipe como especialistas em duas ou nas três das seguintes áreas: saúde mental, determinantes sociais da habitação e elaboração de questionários. Embora nem todos dominassem os três temas simultaneamente, tinham em comum o fato de serem pesquisadores vinculados a diferentes academias, além de inserção e interesses no campo da saúde mental. A maioria dos estudos Delphi privilegia grande número de consultados e tratamento estatístico das opinióes (DESLANDES et al., 2010). No entanto, optamos por adaptar a técnica de Delphi aos nossos intentos e privilegiamos, por um lado, menor número de pessoas consultadas e, por outro, inserimos tanto questóes estruturadas quanto semiestruturadas no roteiro endereçado ao grupo.

Na primeira rodada, foram enviados 56 itens que compunham o conjunto total de questôes distribuídas nos blocos 'Aspectos Clínicos', 'Aspectos Socioeconômicos', 'Condições do imóvel', 'Inserção Social e Autonomia' e 'Habitação e Satisfação' que compunham o instrumento. No roteiro que servia de base para as respostas dos integrantes do grupo Delphi, enviado juntamente com o questionário, deveriam ser respondidas questôes fechadas sobre a clareza, pertinência das 
Departamento Saúde, Educação e Sociedade - Laboratório de Avaliação de Programas e Serviços de Saúde

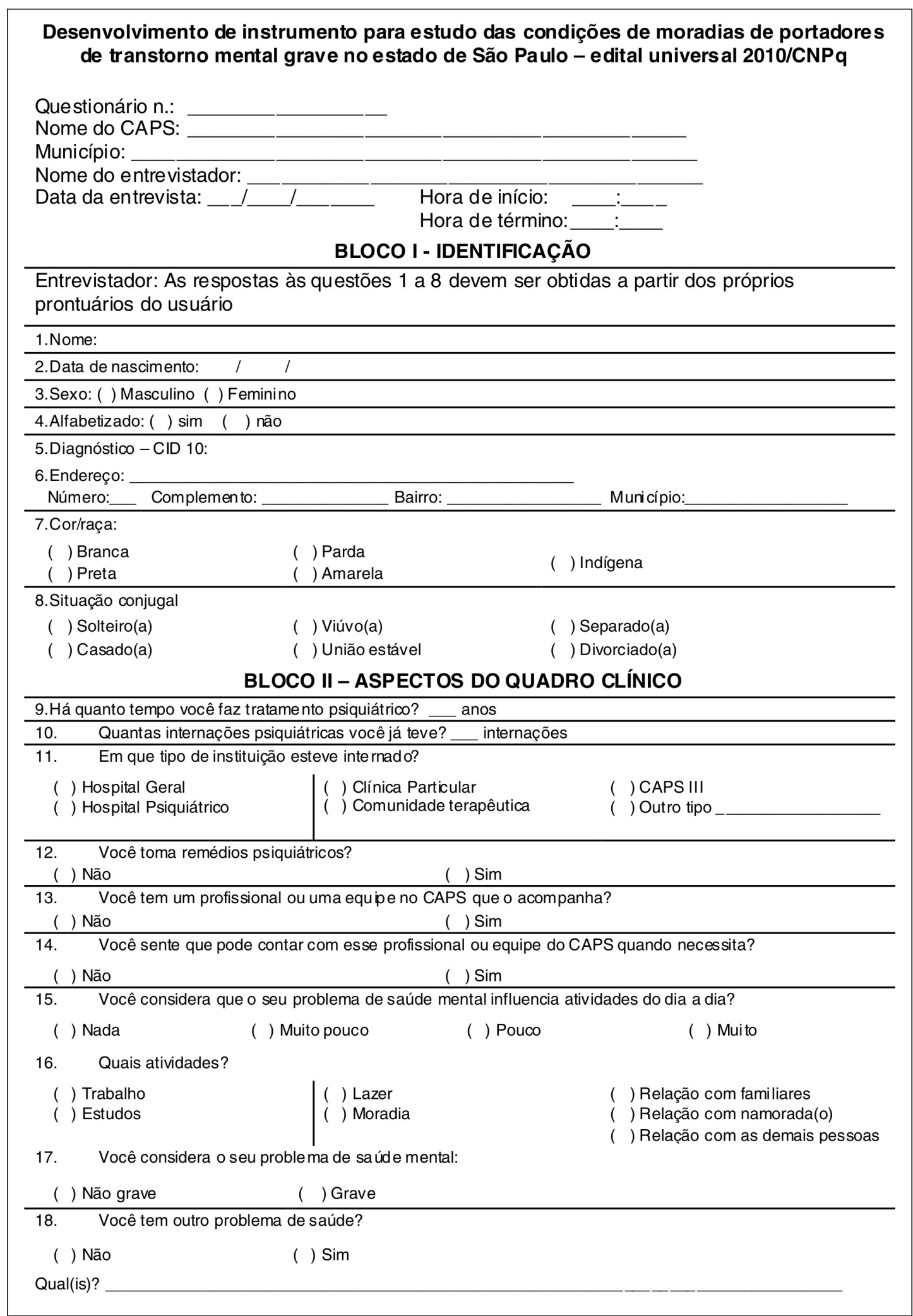




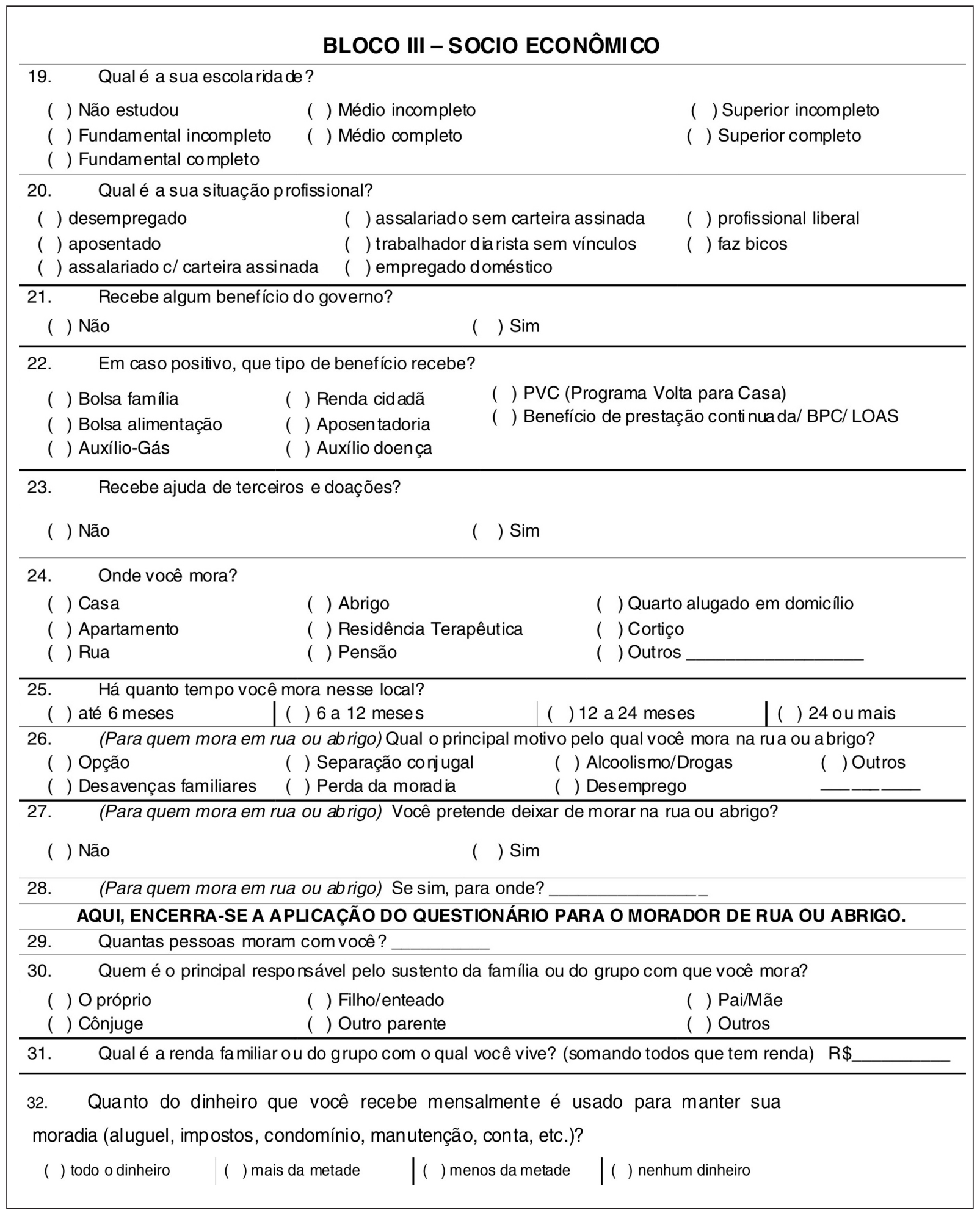




\section{BLOCO IV - CARACTERÍSTICAS DO IMÓVEL}

33. Qual a condição legal de sua moradia?
( ) Própria e quitada
( ) Alugada
( ) Ocupada
( ) Própria e ainda pagando
( ) Cedida

34. A sua moradia está inseri da em?
( ) Favela
( ) Edificação isolada
( ) Prédio de apartamentos
( ) Cortiço
( ) Condomínio fechado

35. Quantos cômodos de cada tipo há no domicílio?

$\begin{array}{lll}\text { Quartos } & \text { Cozinhas } & \text { Banheiros externos } \\ \text { Salas } & \text { Banheiros internos } & \text { Outros }\end{array}$

\begin{tabular}{lll}
\hline 36. Quantas pessoas (excluindo cônjuge) dormem no mesmo cômodo que você? \\
\hline 37. $\quad$ Quais destes serviços atendem a sua moradia? (marque um x naquele que o usuário tem acesso em \\
sua casa) \\
$\begin{array}{lll}\text { ( ) Telefone fixo } & \text { ( ) Rede de esgoto } & \text { ( ) Guias e sarjetas } \\
\text { ( ) Internet } & \text { ( ) Col eta de lixo } & \text { ( ) Pavimentação } \\
\text { ( ) Rede pública de água } & \text { ( ) Transporte público } & \text { ( ) Outros } \\
\text { ( ) Rede pública de ene rgia elétrica } & \text { ( ) lluminação pública }\end{array}$
\end{tabular}

38. Dentre os lugares abaixo, quais estão próximos de sua moradia? (dá pra ir a pé)
( ) Creche
( ) Padaria
( ) Clube
( ) Escola de ensino fundamentalmédio
( ) Açougue
( ) Igrejas
( ) Hospital/Pronto socorro
( ) Farmácia
( ) Caps
( ) Unidade Básica de Saúde
( ) Quitanda/mercearia
( ) Bares
( ) Agência bancária
( ) Supermercado
( ) CRAS
( ) Correios
( ) Centro Comunitário
( ) Centro Comunitário
( ) Comércio em geral
( ) Praça
( ) Posto policial/Delegacia
( ) Quadra de esporte
( ) Unidade de Saúde
( ) Outro

\section{BLOCO V - INSERÇÃO SOCIAL E AUTONOMIA}

39. Dos locais mencionados na questão 35 , no bloco anterior, quais você frequenta?
( ) Creche
( ) Padaria
( ) Clube
( ) Escola de ensino fundamentalmédio
( ) Açougue
( ) Igrejas
( ) Hospital/Pronto socorro
( ) Farmácia
( ) Caps
( ) Unidade Básica de Saúde
( ) Quitanda/mercearia
( ) Bares
( ) Agência bancária
( ) Supermercado
( ) Centro Comunitário
( ) Correios
( ) Associação de Bairro
( ) CRAS
( ) Comércio em geral
( ) Praça
( ) Unidade de Saúde
( ) Posto policial/Delegacia
( ) Quadra de esporte
( ) Outro

40. No dia a dia, com quais pessoas você conversa, fora de seu lugar de moradia?
( ) parentes (que não moram com você)
( ) vizinhos
( ) desconhecidos
( ) profissionais do CAPS/SRT
( ) colegas de trabalho
( ) namorado(a)
( ) outros pacientes do CAPS/SRT ( ) ninguém
( ) comerciantes
( ) pessoas ligadas à igreja


41. O relacionamento com as pessoas que moram com você, no momento atual, é:
( ) bom
( ) regular
( ) ruim
( ) não se aplica

42. Tomando como base, o momento atual, você conversa com as pessoas que moram com você
( ) Muito
( ) Pouco
( ) Nada
( ) Mora sozinho

43. Você costuma sair com algumas das pessoas que moram com você?

\begin{tabular}{l|l} 
( ) Não & ( ) Sim
\end{tabular}

( ) Mora sozinho

44. Você é convidado a participar de festas, comemorações, almoço, churrasco e outros encontros?

\begin{tabular}{l|l|l} 
( ) Sempre & ( ) Às vezes & ( ) Nunca
\end{tabular}

45. Se sim, quem the convida?
( ) familiares
( ) usuários do Caps
( ) CAPS e outras instituições
( ) vizinhos
( ) usuários de outros serviços de saúde
( ) outros
( ) pessoal da igreja
( ) colegas de trabalho

46. Quando você tem um proble ma e precisa de ajuda, quem você procura?
( ) família
( ) pessoal da igreja
( ) pessoal da prefeitura
( ) amigos ou conhecidos
( ) pessoal do Caps
( ) pessoal do abrigo
( ) vizinhos
( ) colegas de trabalho
( ) ninguém

47. Quem procura você quan do precisa de ajuda?
( ) ninguém
( ) vizinhos
( ) família
( ) pessoal da igreja
( ) amigos ou conhecidos
( ) pessoal do abrigo
( ) colegas de trabalho
( ) colegas do CAPS/SRT

48. Quem costuma visitá-lo e m sua casa?
( ) minha familia
( ) o pessoal da igreja
( ) pessoal da p refeitu ra
( ) meus amigos ou conhecidos
( ) o pessoal do Caps
( ) não costumo receber visitas
( ) meus vizinhos

( ) meus colegas de trabalho

49. Você recebe visita de profissionais da saúde (agente comunitário de saúde, médico, enfermeiro ou outro profissional do Caps)?

$$
\text { ( ) Não }
$$

( ) $\operatorname{Sim}$

50. Em caso afirmativo, quan tas ve zes ocorrem as visitas?
( ) diariamente
( ) semanalmente
( ) mensalmente

51. Quais das seguintes atividades você faz sozinho, sem ajuda?

( ) higiene pessoal

( ) ir nos locais de interesse na cida de

( ) receber o seu dinheiro no banco

( ) tomar medicação

( ) realizar compras e pagamentos

\section{BLOCO VI - Habitação e Satisfação}

52. Nos últimos 12 meses, em quantos lugares diferentes você morou?

53. O que motivou a sua útima mudança?

54. Você tem fotos, plantas e/ou ou tros objetos de que você goste especialmente decorando sua casa?

$$
\text { ( ) Não }
$$
( ) Sim

55. Você tem animais de estimação?

$$
\text { ( ) Não }
$$

56. Você gosta de ficar em seu l œal de moradia?
( ) Muito
( ) Um pouco

( ) Não gosto 
57. Você ajuda a cuidar do seu local de moradia?

$$
\begin{array}{l|l}
\text { ( ) Não } & \text { ( ) Sim }
\end{array}
$$

58. Você se sente à vontade para mudar os móveis e a decoração de sua moradia?
( ) Não
( ) Um pouco
( ) $\operatorname{Sim}$

59. Você tem vontade de mudar para outra moradia?
( ) Não
( ) Sim

Avalie sua satisfação com seu local de moradia, de acordo com as características a seguir:

60. Conforto

\begin{tabular}{l|l|l|l|l} 
( ) Nada satisfeito & ( ) Pouco satisfeito & $($ ( ) Indiferente & ( ) Satisfeito & ( ) Muito satisfeito
\end{tabular}

61. Segurança

\begin{tabular}{l|l|l|l|l} 
( ) Nada satisfeito & ( ) Pouco satisfeito & ( ) Indiferente & ( ) Satisfeito & ( ) Muito satisfeito \\
\hline
\end{tabular}

62. Privacidade

\begin{tabular}{l|l|l|l|l} 
( )Nada satisfeito & ( ) Pouco satisfeito & ( ) Indiferente & ( ) Satisfeito & ( ) Muito satisfeito \\
\hline
\end{tabular}

63. Como você se sente em relação ao bairro onde mora?

\begin{tabular}{l|l|l} 
( ) é muito importante viver nesse & ( ) é indiferente viver nesse bairro & ( ) gostaria de mudar desse bairro
\end{tabular}

\begin{tabular}{|c|c|c|c|c|}
\hline \multirow{2}{*}{$\begin{array}{l}64 . \quad \text { Lazer } \\
\text { ( )Nada satisfeito }\end{array}$} & & & & \\
\hline & ( ) Pouco satisfeito & ( ) Indiferente & ( )Satisfeito & ( ) Muito satisfeito \\
\hline \multicolumn{5}{|l|}{ 65. Vizinhança } \\
\hline ( )Nada satisfeito & ( ) Pouco satisfeito & ( ) Indiferente & ( )Satisfeito & ( ) Muito satisfeito \\
\hline \multicolumn{5}{|l|}{ 66. Segurança } \\
\hline ( )Nada satisfeito & ( ) Pouco satisfeito & ( ) Indiferente & ( )Satisfeito & ( ) Muito satisfeito \\
\hline \multicolumn{5}{|l|}{ 67. Comércio } \\
\hline ( )Nada satisfeito & ( ) Pouco satisfeito & ( ) Indiferente & ( )Satisfeito & ( ) Muito satisfeito \\
\hline
\end{tabular}

Avalie sua satisfação com se u bairro, de acordo com as características a seguir:

68. Serviços públicos

\begin{tabular}{l|l|l|l|l} 
( ) Nada satisfeito & ( ) Pouco satisfeito & ( ) Indiferente & ( ) Satisfeito & ( ) Muito satisfeito
\end{tabular}

69. Transporte

\begin{tabular}{l|l|l|l|l} 
( ) Nada satisfeito & ( ) Pouco satisfeito & ( ) Indiferente & ( ) Satisfeito & ( ) Muito satisfeito
\end{tabular}

70. Proximidade a serviços de saúde
( )Nada satisfeito
( ) Pouco satisfeito ( ) Indiferente
( ) Satisfeito
( ) Muito satisfeito

71. Há algo que você gosta ria de falar a respeito desse tema e que não foi pergun tado? 
categorias utilizadas e articulação com os objetivos do estudo. Além disso, para cada item havia um campo aberto para sugestôes, críticas e comentários pertinentes. Finalmente, ao final de cada um dos cinco blocos, outro campo aberto destinava-se aos comentários gerais de apreciação do respectivo bloco como um todo, sobretudo em relação à capacidade do mesmo em extrair dados de interesse e pertinência ao tema ali abordado.

\section{Contribuiçóes oriundas do Delphi}

As contribuiçóes oriundas da primeira rodada foram agrupadas segundo o item e bloco a que pertenciam. As críticas e sugestóes foram concernentes à adequação do uso de determinados termos e, conforme o caso, ao desdobramento ou aglutinação de questôes. Abaixo ilustramos, com alguns exemplos, alteraçóes decorrentes da primeira rodada do Delphi.

- Adequação do uso de termos: correção de jargão e palavras que poderiam dificultar a compreensão da pergunta pelos futuros entrevistados. Assim, por exemplo, foi sugerida a troca da pergunta 'Você tem um profissional de referência no CAPS?' por 'Você tem um profissional ou uma equipe no CAPS que o acompanha?' e da expressão 'interagir' por "conversar". Ainda nesse sentido, foi amplamente recomendado evitar o uso de sinônimos (como moradia, casa, domicílio, imóvel etc. para se referir ao local de morada dos entrevistados), unificando termos centrais ao estudo; e a substituição de termos pejorativos como 'imóvel ocupado irregularmente' por 'ocupação'.

- Desdobramento de questóes: algumas questóes foram acrescentadas a partir das contribuições provenientes do Delphi. Assim, à pergunta sobre eventuais influências do problema de saúde mental sobre atividades da vida, foi sugerida e incorporada outra, indagando sobre quais seriam essas atividades afetadas (trabalho, estudos, moradia, lazer etc.).
À pergunta 'Onde você mora?' acrescentou-se outra sobre 'Há quanto tempo você mora nesse local?', agregando importante dimensão de permanência no tempo, ao que foi indagado. Algo semelhante ocorreu à pergunta sobre comércio e espaços públicos existentes nas imediaçóes da casa. A essa pergunta foi acrescida outra, especificando, entre os equipamentos existentes na proximidade, quais são frequentados pelo respondente.

- Aglutinação de questôes: algumas redundâncias foram excluídas e condensadas em um só item, auxiliando a diminuir o número final de questôes. $\mathrm{Na}$ versão original, três questóes (com respostas 'sim' e 'não') sobre a necessidade de ajuda para realizar atividades de vida diária foram modificadas a partir das contribuições, tornando-se uma só questão assim formulada: 'Quais das seguintes atividades você faz sozinho, sem precisar de ajuda?', seguida de cinco opçóes a serem ou não marcadas.

Algumas questóes levantadas pelos especialistas do Delphi não foram efetivamente consideradas. Tal foi o caso de termos considerados pouco claros, como 'conforto' e 'privacidade' e redundâncias identificadas nas questôes constantes no bloco 'Habitação e Satisfação'. Após várias discussões, os pesquisadores responsáveis pelo instrumento não encontraram termos ou expressóes mais esclarecedoras sobre noçôes de 'conforto' e 'necessidade', por exemplo. Da mesma forma, chegouse à conclusão de que a aparente redundância sobre o grau de satisfação representava deliberado esforço em captar o grau de contentamento do entrevistado com sua situação de moradia e o entorno da mesma.

Salientamos que tanto no roteiro proposto aos integrantes do Delphi quanto nos trabalhos da equipe de pesquisadores, privilegiamos os critérios propostos por Blais e Durand (2004) para balizar a qualidade das questôes: precisão (correspondência dos termos ao que se pretende saber e familiaridade com os mesmos por parte do grupo estudado), pertinência (perguntas 
realmente adequadas e aplicáveis àqueles a quem indagamos) e neutralidade (no sentido de evidenciar o que o respondente realmente faz ou pensa e não o que os pesquisadores gostariam que ele fizesse ou pensasse).

Após processamento e análise das contribuições iniciais, o questionário modificado foi submetido pela segunda e última vez aos interlocutores por meio da técnica de Delphi. Houve consenso absoluto em torno da nova proposta, que incorporava boa parte das sugestôes, e não foram propostas novas modificaçóes pelos integrantes do grupo Delphi, sendo que alguns espontaneamente ressaltaram a qualidade e a adequação do instrumento final.

\section{Contribuiçóes oriundas do contexto de aplicação: o estudo piloto}

A despeito dos subsídios provenientes do Delphi e de criteriosas discussōes da equipe responsável, várias questóes sobre o questionário somente poderiam ser elucidadas por meio da aplicaçấo junto à clientela visada, configurando pré-testes (CARVALHO et al., 2010; FAERSTEIN, 1999). Nesta fase do estudo, procurouse conhecer a reação dos entrevistados quanto à duraçấo, clareza e pertinência do questionário e se as questóes continham as alternativas necessárias, na ordem adequada e sem influenciar negativamente a pergunta seguinte.

Para Babbie (1999), os pré-testes seriam testes iniciais de um ou mais aspectos do desenho e/ou do instrumento de pesquisa, enquanto os estudos piloto se referem a exames em dimensão reduzida de todo o desenho da pesquisa. Nesse sentido, podemos caracterizar nosso trabalho de campo não como 'pré-teste', mas muito mais apropriadamente como 'estudo piloto', uma vez que não só o questionário, mas toda a concepção de como aplicá-lo foi implementada no primeiro teste.

Em função das características da população-alvo do questionário, o mesmo foi elaborado para ser aplicado por trabalhadores dos CAPS, após treinamento específico, junto a usuários desses mesmos serviços. Desse modo, o vínculo preexistente poderia superar eventuais dificuldades e desconfianças apresentadas pelo públicoalvo. Além disso, os trabalhadores apresentam especiais condiçôes de, caso necessário, dirimir dificuldades de entendimento de uma ou outra questáo, além de facilitarem sobremaneira o efetivo acesso à clientela.

Assim sendo, seis trabalhadores de três Centros de Atenção Psicossocial, de diferentes municípios, foram treinados com o questionário propriamente dito, acompanhado de outro formulário destinado a receber anotaçóes de questóes explicitadas pelos entrevistados ou percebidas por eles próprios no transcorrer da entrevista. Entre as questóes presentes no formulário, deveriam constar eventuais hesitaçóes, não compreensóes e dificuldades dos entrevistados, conforme proposto por Blais e Durand (2004). Cada trabalhador aplicou cinco questionários, totalizando 30 aplicaçóes, que foram apresentadas e discutidas junto aos pesquisadores para a identificação das possibilidades e limitações do instrumento em contexto real. Após esta etapa de aplicação do questionário, estes trabalhadores que aplicaram o instrumento retornaram à equipe de pesquisadores para devolutivas e análise da situação-teste. As análises iniciais partiram de aspectos gerais para aplicação do questionário seguidas de consideraçóes sobre cada uma das perguntas feitas e do conteúdo das mesmas.

Dentre os aspectos gerais, os aplicadores destacaram que, em função de o público-alvo de respondentes serem pessoas com grave sofrimento psíquico, atividades delirantes eventualmente perpassaram a entrevista. Nesse caso, os entrevistadores tiveram o cuidado de, mais tarde, retomar o tema que teria sido afetado naquele momento pelas alteraçóes apresentadas pelo entrevistado. No geral, segundo os aplicadores do questionário no estudo piloto, a linguagem usada no questionário é mais adequada aos aplicadores que ao público entrevistado. Foram vários os exemplos que os aplicadores apresentaram de questóes às quais foi necessário lançar mão de sinônimos e explicações de modo a atingir efetiva compreensão por parte do entrevistado. Nesse sentido, palavras como 'relacionamento' eram mais bem compreendidas como 'convivência', 'privacidade' como 'se sentir à vontade', além de outras que requeriam explicação e exemplos, como 'serviços públicos'.

A clareza, concisão e adaptação ao público-alvo são fundamentais na elaboração das questôes de um questionário (HILL; HILL, 2012; VIEIRA, 2009). No entanto, nossa proposta direciona-se a dois públicos 
simultaneamente: àqueles que darão respostas e àqueles que aplicarão os questionários. Nesse sentido, optamos por deixar as questóes com os termos mais próximos, acessíveis e claros a esse último grupo, mas considerando as dificuldades de compreensão geradas por certos termos para os futuros treinamentos de aplicação do instrumento.

As situações referidas justificam a importância de que o aplicador do instrumento seja trabalhador de serviços de saúde ou que já tenha inserção no campo da saúde mental e habilidade no manejo de situações em que produçóes psicóticas se apresentam. Além do que, assim o aplicador também pode ilustrar situaçóes relativas à vida do respondente, como também poderá esclarecer palavras e situaçóes para a realidade do entrevistado. Além disso, questóes que envolviam alternativas como 'muito', 'pouco', 'nada' exigiram inflexão e certa teatralizaçáo de voz por parte do entrevistador. Os aplicadores destacaram que, ao final, tanto entrevistador quanto entrevistado sentiam e davam mostras de certo cansaço, momento que exigiu empenho para que a tarefa não fosse feita de maneira automática e alienada. Por fim, cada questionário exigiu em média 45 minutos para ser respondido, superando expectativas iniciais dos aplicadores que previam mais dificuldade e consequentemente mais tempo para a aplicação do mesmo.

\section{Considerações Finais}

Desenvolver um instrumento para estudo das condiçóes de moradia de pessoas com sofrimento psíquico grave no novo contexto da saúde mental brasileira impôs, primeiramente, o desafio de sua construção na perspectiva interdisciplinar. Desde o início, a configuração da proposta do projeto de pesquisa articulou pesquisadores das áreas de Saúde Coletiva, Psicologia, Serviço Social e Estatística numa perspectiva interdisciplinar e buscou consolidar um espaço de relaçóes, partilha e articulação de saberes e práticas.

Esse processo interdisciplinar de produção do conhecimento, por meio do desenvolvimento do questionário, mostrou-se bastante pertinente, especialmente porque abordar as condiçóes de moradia de pessoas com sofrimento psíquico grave requer a análise de situações complexas, síntese de múltiplas determinaçóes sociais, econômicas, históricas, políticas e culturais.

Por esse entendimento, o questionário foi construído e reconstruído a partir da tríade de questóes: por que fazer, para que fazer e como fazer o estudo das condiçóes de moradia dos referidos sujeitos. O desenvolvimento desse instrumento não se reduziu à dimensão tecnoperativa, ao modus operandi, ao simples manejo da técnica. Sua objetivação conectou-se à capacidade e qualidade dos referentes teóricos, políticos, éticos e metodológicos adotados por nós e consolidados a partir do debate qualificado com os especialistas e trabalhadores dos CAPS, partícipes deste processo.

O questionário permitiu abordar fatos (onde moram, quais as condiçóes da moradia - aspectos da vida material) e processos (alternativas e estratégias de moradia encontradas, inserção e autonomia, formas de morar, aspectos da vida social) que conformam a situaçáo atual de moradia dos portadores de sofrimento psíquico grave em um contexto de desinstitucionalização.

É certo que o questionário como instrumento estruturado de investigação tem limites, pois recorta a realidade, explora uma dimensão da vida social e material e conforma com mais propriedade o terreno da pesquisa quantitativa. Entretanto, apresenta uma enorme potencialidade para descobrir, criar e expandir o conhecimento das complexas determinaçóes que conformam o morar na atualidade.

O lugar do questionário como produto da instrumentalidade dessa pesquisa está assentado no plano da produção do conhecimento, ao compor a dinâmica da relação teoria e realidade; no âmbito do trabalho profissional ao colocar, iluminar um problema e convidar para refletir e intervir em situaçôes que emergem no cotidiano, e na singularidade dos sujeitos e, na lógica organizacional dos serviços, em especial dos CAPS, por considerar sua capilaridade institucional e proximidade dos territórios de vida dos portadores de sofrimento psíquico grave.

Alinhados às formas de produção de conhecimento que defendemos (FURTADO; ONOCKO CAMPOS, 2008), desde o princípio adotamos alguns elementos centrais e estratégicos para a validação e expansão da 
metodologia de construção do instrumental: a interação entre Universidade e serviços (nos processos de desenvolvimento e aplicação do questionário), mais diretamente, com os trabalhadores dos CAPS e entre a equipe de pesquisadores e especialistas da área. Consideramos que o envolvimento desses sujeitos que atuam diretamente no campo da produção do conhecimento e dos serviços pode aproximar e disparar processos que contribuam para o aperfeiçoamento da reforma do modelo assistencial em curso.
Além da queda dos muros, permanece o desafio de conhecer para intervir nas condiçóes e necessidades de moradias dos sujeitos que vivem com sofrimento psíquico grave. O questionário (em anexo) produzido neste estudo pode tornar-se uma referência para o levantamento sistemático e em larga escala das condiçóes e necessidades de moradia de portadores de sofrimento psíquico grave no estado de São Paulo, subsidiar estratégias de enfrentamento e proposição de alternativas no âmbito da Reforma Psiquiátrica e gerar novos estudos em torno da temática.

\section{Referências}

ALMEIDA, I. ; CASTRO, P. Realojamento - satisfação residencial e identidade local. In: I COLÓQUIO PSICOLOGIA, ESPAÇO E AMBIENTE. Universidade de Évora, 2002.

AMARANTE, P. (org.). Psiquiatria social e reforma psiquiátrica. Rio de Janeiro: FIOCRUZ, 1994. 132 p.

ARIÈS, P. História Social da Criança e da Família. 2. ed. Rio de Janeiro: Editora Guanabara, 1986. 280 p.

BABBIE, E. Métodos de pesquisas de Survey. Belo Horizonte: UFMG, 1999. 311 p.

BARROS, S.; BICHAFF, R. (Org.). Desafios para a desinstitucionalização: censo psicossocial dos moradores em hospitais psiquiátricos do estado de São Paulo. São Paulo: FUNDAP, Secretaria da Saúde, 2008. 169 p.

BEAULIEU A; DORVIL, H. (Orgs.). L'habitation comme détermiant social de la santé mentale. Montreal: Acfas, 2004. 189 p. AZEREDO,

C. M. et al. Avaliação das condições de habitação e saneamento: a importância da visita domiciliar no contexto do Programa de Saúde da Família. Ciência e Saúde Coletiva, Rio de Janeiro, v. 12, n. 3, p. 743-753, 2007.

BLAIS, A.; DURAND, C. Le sondage. In: GAUTHIER, B. (Org.) Recherche Sociale: de la problématique à la collecte des données. Sainte-Foy: Presses de l'Université du Québec, 2004. p. 387-430.

BRANDÃO, L. A casa subjetiva. São Paulo: Editora Perspectiva, 2002. $176 \mathrm{p}$.

BRASIL. Ministério da Saúde. Residências terapêuticas: que são? Para que servem? Brasília: Secretaria de Atenção à Saúde, Departamento de Ações Programáticas e Estratégicas, 2004.

Ministério da Saúde. Coordenação Geral de Saúde Mental, Álcool e Outras Drogas. Saúde Mental em Dados. Brasília: Coordenação Geral de Saúde Mental, Álcool e Outras Drogas,
2012. 28 p. Disponível em: <http://www.saude.gov.br>. Acesso em: 10 maio 2012

CARVALHO, F. S. et al. Desenvolvimento e pré-teste de um questionário de frequência alimentar para graduandos. Revista de Nutrição, Campinas, v. 23, n. 5, p. 847-857, 2010.

DESLANDES, S. F. et al. Use of the nominal group technique and the Delphi Method to draw up evaluation indicators for strategies to deal with violence against children and adolescents in Brazil. Revista Brasileira Saúde Materno Infantil, Recife, v. 10, supl. 1, p. 529537, 2010.

FAERSTEIN, E. et al. Pré-teste de um questionário multidimensional autopreenchível: a experiência do estudo pró-Saúde UERJ. Physis: Revista de Saúde Coletiva, Rio de Janeiro, v. 9, n. 2, p. 117-130, 1999.

FOUCAUlT, M. História da loucura. São Paulo: Perspectiva, 1991. $551 \mathrm{p}$.

FURTADO, J. P. Equipes de referência: arranjo institucional para potencializar a colaboração entre disciplinas e profissões. Interface: Comunicação, Saúde e Educação, Botucatu, v. 11, p. 239-255, 2007.

Avaliação da situação atual dos Serviços Residenciais Terapêuticos existentes no SUS. Ciência \& Saúde Coletiva, Rio de Janeiro, v. 11, p. 785-795, 2006.

FURTADO, J. P. et al. Inserção social e habitação: um caminho para a avaliação da situação de moradia de portadores de transtorno mental grave no Brasil. Interface: Comunicação, Saúde e Educação, Botucatu, v. 14, p. 389-400, 2010.

FURTADO, J. P.; ONOCKO CAMPOS, R. Participação, produção de conhecimento e pesquisa avaliativa: a inserção de diferentes atores em uma investigação em saúde mental. Cadernos de Saúde Pública, Rio de Janeiro, v. 24, p. 2671-2680, 2008. 
FURTADO J. P.; PACHECO, R.A. Moradias para pacientes psiquiátricos em Campinas: análise de uma experiência. Jornal Brasileiro de Psiquiatria, Rio de Janeiro, v. 4, p. 44-57, 1998.

HILL, M. M.; HILL, A. Investigação por questionário. Lisboa: Sílabo, 2012. 377 p.

INSTITUTO BRASILEIRO DE GEOGRAFIA E ESTATÍSTICA (IBGE). Um panorama da Saúde no Brasil: acesso e utilização dos serviços, condições de saúde e fatores de risco e proteção à saúde. Rio de Janeiro: IBGE, 2009.

JONES, J.; HUNTER, D. Qualitative research: consensus methods for medical and health services research. British Medical Journal, London, v. 311, n. 7001, p. 376-380, 1995.

KANTORSKI, L. P. et al. Avaliando a política de saúde mental num CAPS: a trajetória no movimento antimanicomial. Estudos e Pesquisas em Psicologia, Rio de Janeiro, v. 1, p. 242-263, 2010.

LANDETA, J. El método Delphi: una técnica para previsión de La Incertidumbre. Barcelona: Editora Ariel, 1999. 191 p.

MOREIRA, M. I. B. Se esta casa fosse minha: habitar e viver na cidade a partir de uma residência terapêutica. 2007. 186 f. Tese (Doutorado em Psicologia) - Universidade Federal do Espírito Santo, Vitória, 2007.

MORIN, P.; DORVIL H. Dossier: Le logement social et I'hebergement. Nouvelles Pratiques Sociales, Montreal, v. 14, n.2, 2001

PIOLA, S.F. ; VIANNA, S.M ; VIVAS-CONSUELO, D. Estudo Delphi: atores sociais e tendências do sistema de saúde brasileiro, Rio de Janeiro, Cadernos de Saúde Pública vol.18 suppl. p. 181-190, 2002

RAICHELIS, R. Democratizar a gestão das políticas sociais: um desafio a ser enfrentado pela sociedade civil. In: MOTA, A. E. et al.
Serviço Social e Saúde: formação e trabalho profissional. Brasília: OPAS, 2006. 17 p. Disponível em:< http://www.fnepas.org.br/pdf/ servico_social_saude/texto1-4.pdf>. Acesso em: 28 ago. 2011.

RYBCZYNKI, W. CASA. Pequena historia de uma ideia. Rio de Janeiro: Editora Record, 1996. 259 p.

SÃO PAULO. Fundação Sistema Estadual de Análise de Dados (SEADE). Pesquisa de Condições de Vida no Estado de São Paulo. São Paulo: SEADE, 2006. Disponível em: <http://www.seade.gov.br/ produtos/pcv/index.php >. Acesso em: 10 maio 2011.

SARACENO, B. Reabilitação como cidadania. In: - Libertando identidades: da reabilitação psicossocial à cidadania possível. Rio de Janeiro: TeCorá, 1999. 208 p.

SENNET, R. O Declínio do homem publico: as tiranias da intimidade. São Paulo: Companhia das Letras, 1988. 447 p.

SPOSATI, A. Assistência Social: de ação individual a direito social. Revista Brasileira de Direito Constitucional (RDBC), São Paulo, n. 10, jul./dez. 2007. Disponível em: <http://www.esdc.com.br/ RBDC/RBDC-10/RBDC-10-435-Aldaiza_Sposati.pdf>. Acesso em: 29 ago.2011.

THOMSON, H. et al. M. The Health Impacts of Housing Improvement: a systematic review of intervention studies from 1887 to 2007. American Journal Public Health, Washington, v. 3, suppl., 99-S3, 2009.

VETTER, D. M. Problemas conceituais e operacionais na avaliação da "adequação" das condições residenciais através de indicadores elaborados com dados dos Censos e das PNADs. Revista Brasileira de Estatística, Rio de Janeiro, v. 42, n. 168, p. 291-412, 1981.

VIEIRA, S. Como Elaborar Questionários. São Paulo: Atlas, 2009. 211 p.
Recebido para publicação em Setembro/2012

Versão final em janeiro/2013

Conflito de interesse: não houve 